\title{
Anticoncepção e Gravidez na Adolescência: Elaboraçáo de um vídeo para os adolescentes
}

\section{Contraception and Adolescent Pregnancy: Preparation of a video for teens}

Alessandra dos Santos Lima ${ }^{1}$

Maria de Fátima Alves de Oliveira ${ }^{2}$

\begin{abstract}
Resumo
A adolescência marca a transição entre a infância e a idade adulta e caracteriza-se por alteraçóes nos níveis: físico, mental e social. Representa para o indivíduo um processo de distanciamento de formas de comportamento da infância e aquisição de características que o capacitem a assumir o papel social do adulto. A gravidez na adolescência entra neste contexto com implicaçóes diversas atingindo a grávida, seus familiares e a sociedade como um todo. A escola é fundamental na educação em saúde e na formação dos adolescentes, podendo ser apontada como o local mais adequado de preparação dos jovens para a vida em sociedade. Entre os recursos didáticos utilizados no contexto escolar, a inserção de novas ferramentas está fazendo com que o professor esteja preparado para utilizar as novas tecnologias educacionais a favor do aprendizado. Esta pesquisa tem como objetivo elaborar um recurso didático, no formato de um vídeo, com orientaçóes contraceptivas para adolescentes, que estejam nos últimos anos do ensino fundamental, a fim de dar subsídios à prevenção da gravidez nesta fase da vida. Para coleta de dados foi aplicado um questionário a gestantes adolescentes entre 10 e 19 anos da Policlínica da Mulher do Aterrado de Volta Redonda - RJ. Após análise dos dados identificou-se diferentes motivos que levaram à gravidez precoce e com base nestes dados o vídeo foi elaborado.
\end{abstract}

Palavras-chave: Gravidez; anticoncepção; adolescência, vídeo

\begin{abstract}
Adolescence marks the transition between childhood and adulthood and is characterized by changes in levels: physical, mental and social. Represents for the individual process of distancing forms of childhood behavior and acquiring characteristics that enable them to assume the role of the adult social. Teenage pregnancy enters this context with different implications reaching pregnant, their families and society as a whole. The school is essential in health education and training of adolescents and may be cited as the most suitable place to prepare young people for life in society. Among the teaching resources used in the school context the inclusion of new tools is causing the teacher is prepared to use new educational technologies for learning. This research aims to develop a teaching resource, in a video format, with guidelines contraception for teenagers, who are in the last years of elementary school in order to make allowances for pregnancy prevention at this stage of life. For data collection a questionnaire was administered to pregnant adolescents between 10 and 19 years of the Women's Polyclinic Grounded Volta Redonda - RJ. After analyzing the data we identified different reasons that led to early pregnancy and based on these data the video was produced.
\end{abstract}

Keywords: Pregnancy, contraception, adolescence, video

\footnotetext{
${ }^{1}$ Graduada em Medicina, pós-graduado em ginecologia e obstetrícia e, mestranda em Ensino em Ciências da Saúde e do Meio Ambiente do UNIFOA - Centro Universitário de Volta Redonda.

2 Professora do LAEFIB/IOC/Fiocruz e do Mestrado Profissional em Ensino em Ciências da Saúde e do Meio Ambiente do UNIFOA - Centro Universitário de Volta Redonda.
} 


\section{INTRODUÇÃO}

A Organização Mundial de Saúde define a adolescência como a fase do desenvolvimento humano compreendida entre 10 e 19 anos, critério adotado no Brasil pelo Ministério da Saúde (2006) e pelo Instituto Brasileiro de Geografia e Estatística (IBGE). A "adolescência" é um termo geralmente utilizado em um contexto científico com relação ao processo de desenvolvimento bio-psico-social do indivíduo, determinado por fatores genéticos e ambientais (VIEIRA et al., 2006).

$\mathrm{O}$ início da adolescênica é marcado por um período conhecido como puberdade. Esse período geralmente está compreendido entre 12 e 15 anos nas meninas e entre 13 e 16 anos nos meninos. A puberdade caracteriza-se por ocorrer mudanças no sistema reprodutor do ser humano, tornando-o apto a produzir gametas (óvulos e espermatozóides) e gerar novos indivíduos, adaptando o jovem à procriação. É nessa fase que ocorrem as mudanças físicas no corpo das meninos e meninas, tais como: o aumento da estatura, mudanças na tonalidade da voz, aumento na quantidade de pêlos no corpo, desenvolvimento de seios, ocorrência da primeira menstruação, mudanças no formato do corpo, entre outros. A partir da puberdade também ocorrem mudanças comportamentais, e os meninos e meninas começam a demonstrar interesses relacionados à sexualidade, podendo surgir muitos conflitos (FAVALI et al., 2009).

A maturidade dos órgãos da reprodução não corresponde necessariamente à maturidade sexual. Os humanos se tornam capazes, biologicamente, de reprodução aos 12-13 anos, enquanto a personalidade ainda vai se constituir até a maturidade por mais uma década, resultando em um indivíduo fisicamente apto à reprodução mas ainda imaturo psiquicamente (ALVARENGA et al., 2008). Na maioria dos animais, o sexo relaciona-se exclusivamente à reprodução. Nos seres humanos, porém, sexo tem a ver com muitos outros aspectos: corpo, crescimento, gravidez, constituição de família, amor, amizade, intimidade, prazer, respeito, responsabilidade e saúde (SANTANA \& FONSECA, 2009). Portanto, ser adolescente é, entre outras coisas, não ser mais criança. Mas também significa não ser adulto ainda, o que torna a adolescência uma fase muito especial, cheia de inquietaçôes, descobertas e significados (FAVALI et al., 2009).

Quando se fala em maturidade sexual é necessário lembrar que o tema sexualidade está presente em diversos espaços além dos escolares e ultrapassa fronteiras disciplinares e de gênero, permeia conversas entre meninos e meninas e é assunto a ser abordado na sala de aula pelos diferentes especialistas da escola. É tema de capítulos de livros didáticos, internet, bem como de músicas, danças e brincadeiras que animam recreios e festas (ALTMANN, 2001).
De acordo com o Ministério da Saúde (2006), estima-se que no Brasil, um milhão de adolescentes dá a luz a cada ano, o que corresponde a $20 \%$ do total de nascidos vivos, e a cada ano, registra-se o nascimento de mais de 14 milhóes de crianças, pertencendo suas mães ao segmento adolescente. Os motivos pelos quais as adolescentes engravidam são diversos destacando-se a falta de informação, fatores sociais, falta de acesso a serviços específicos para atender essa faixa etária, o início cada vez mais precoce de experiências sexuais e a insegurança do adolescente em utilizar métodos contraceptivos (DIAS \& TEIXEIRA, 2010; KRAFT, 1993).

Assim, tem-se o conhecimento dos diferentes motivos que contribuem para uma gravidez entre os adolescentes, mas neste estudo, o objetivo é identificar os motivos pelos quais as adolescentes do município de Volta Redonda-RJ engravidam e criar um instrumento que auxilie na prevenção. A partir dos dados coletados por um questionário, será elaborado um vídeo para dar subsídios à prevenção da gravidez na adolescência, com o intuito de disseminá-lo em espaços formais (nas escolas públicas e privadas) e em espaços não formais.

Este tema é relevante porque faz-se necessária a implementação de estratégias que permitam aos jovens desse grupo etário conscientizar-se sobre a importância que envolve a saúde sexual e reprodutiva, pois educar um filho exige dos pais maturidade, condiçóes financeiras e cuidados especiais. Antes de ter uma relação sexual, é preciso pensar nas consequências e a responsabilidade é tanto do homem quanto da mulher. Portanto, é importante para o adolescente dialogar, sem juízo de valor, sobre suas dúvidas e vivências, o que poderia prevenir e garantir uma adolescência saudável.

Um dos motivos mais importantes para a ocorrência da gravidez na adolescência é o fato de que os adolescentes mantêm relaçóes sexuais sem cuidados contraceptivos. Portanto, dois comportamentos precisam existir para que ocorra a gravidez na adolescência: a atividade sexual do jovem e a falta de medidas contraceptivas adequadas.

A pesquisa de Moreira et al. (2008) mostrou que gravidez na adolescência não é de alto risco, contanto que a adolescente tenha um acompanhamento adequado, boa alimentação, cuidados higiênicos necessários e apoio emocional. Também não é um problema da sociedade moderna, porque em todas as épocas as mulheres engravidaram na adolescência. O problema da sociedade moderna é a gravidez indesejada na adolescência, que ocorre de forma desestruturada.

A justificativa da escolha deste tema, deve-se ao fato da autora do trabalho estar inserida em um PSF (Programa de Saúde da Família) e integrar o corpo clínico de hospitais públicos e privados, onde foi observado o aumento relativo do número de adolescentes grávidas, gerando a necessidade de investigar o motivo desse aumento. O presente estudo se 
dedica assim a identificar os motivos e criar um instrumento que auxilie na prevenção da gravidez na adolescência, no município de Volta Redonda-RJ.

\section{CAMINHO METODOLÓGICO:}

A metodologia da pesquisa realizada foi descritiva exploratória, com abordagem quantitativa. $\mathrm{O}$ público alvo são gestantes adolescentes com idade entre 10 e 19 anos, que fazem pré natal no município de Volta Redonda, RJ, local do estudo.

O questionário foi o instrumento de pesquisa escolhido para coleta de dados e apresentava um cabeçalho solicitando a colaboração das adolescentes ao respondê-lo. $\mathrm{O}$ questionário foi aplicado nos meses de março, abril e maio do ano de 2012, contém doze perguntas objetivas relacionadas ao perfil da adolescente em relação a idade, estado civil, parceiro, renda familiar, escolaridade, assuntos discutidos no ambiente escolar, métodos anticoncepcionais e planejamento da gravidez.

A finalidade do questionário é pontuar os conhecimentos prévios das gestantes adolescentes e avaliar alguns dados sócio-econômicos destas gestantes para entender de que modo pode-se contribuir para amenizar a situação, contextualizando o conhecimento referente à sexualidade no processo educativo. Foi explicado o motivo da realizaçáo da pesquisa, antes que respondessem ao questionário.

A partir dos dados coletados e analisados optou-se pela elaboração de um vídeo educativo contendo informaçóes sobre orientaçóes contraceptivas preventivas da gestação na adolescência. Orientações estas, embasadas no conteúdo bibliográfico estudado sobre o tema, cumprindo as exigências do Programa de Mestrado em Ensino de Ciências da Saúde e do Meio Ambiente - UniFOA. (MECSMA).

Antes de responderem ao questionário, as participantes e/ou seus responsáveis (quando menores de idade) assinaram o Termo de Consentimento Livre e Esclarecido (anexo1), recomendado pelo Comitê de Ética em Pesquisa em Seres Humanos (CoEPS) do Centro Universitário de Volta Redonda - UniFOA, que aprovou o projeto deste estudo de acordo com o processo número 053/11, datado em 14 de Março de 2012, em Volta Redonda - RJ.

As respostas obtidas foram agrupadas e categorizadas. Os dados descritivos foram colocados em planilhas e submetidos à análise com auxílio do Programa Microsoft Excel. Para compreensão do leitor, foram apresentados em tabelas e, posteriormente, discutidos e analisados.

$\mathrm{O}$ produto final originado deste estudo consiste em um vídeo no formato de DVD, que encontra-se em fase de edi- toração. A construção das imagens e produção do vídeo serão produzidas por um profissional de artes gráficas, à partir das discussóes e orientaçóes originadas das pesquisas. $\mathrm{O}$ vídeo retrata a conversa entre duas adolescentes sobre métodos contraceptivos após consulta a um ginecologista e os cuidados que devem ser tomados nas relaçóes entre os parceiros.

A disseminação do produto será realizada nas escolas públicas e privadas da região para alunos do 3 últimos anos do ensino fundamental: sétimo, oitavo e nono anos, que correspondem a adolescentes com 12, 13 e 14 anos de idade respectivamente. As escolas serão notificadas para um primeiro contato sobre o tema objeto do estudo e sobre o vídeo (DVD). Será marcada uma palestra com os jovens e o vídeo será apresentado. $\mathrm{O}$ mesmo ficará na escola para ser utilizado em outros momentos pelos professores.

\section{RESULTADOS E DISCUSSÃO:}

O questionário foi aplicado no momento da consulta de pré natal à 51 gestantes adolescentes. Os dados foram tabulados e analisados.

As respostas dos questionários mostram que em relação à idade, conforme a Figura 1 verifica-se dentro da amostra estudada que a maioria das adolescentes está na faixa etária de 15 a 17 anos, ou seja, elas estão na transição do ensino fundamental para o ensino médio. E infelizmente, como relata Moreira et al. (2008), os sistemas convencionais de ensino não dispóem de estrutura adequada para acolher uma adolescente grávida, o que pode gerar como consequência a descontinuidade da escolarização. A interrupçáo de seus estudos durante a gestação ou após o nascimento da criança pode acarretar perdas de oportunidades e piora da qualidade de vida no futuro.

A segunda pergunta do estudo foi referente ao fato de trabalharem ou não, sendo evidenciado que a maioria não trabalha: 47 (92\%) não trabalham e apenas 4 (8\%) trabalham. Portanto, este dado indica que elas são menores de idade sem escolaridade completa da educação básica, o que reflete na dependência financeira dos seus responsáveis. A dependência financeira é mostrada também por alguns outros autores que descrevem como a gravidez compromete a capacidade de autonomização por parte da adolescente em relação às figuras parentais (tarefa que caracteriza o período da adolescência) introduzindo certa ambivalência na relação, já que ao ser mãe há uma precipitação desta autonomia, embora na maioria dos casos, persista uma dependência a nível econômico relativamente aos seus pais (FIGUEIREDO, 2001; CERQUEIRA-SANTOS et al., 2010).

Ao serem questionadas quanto ao estado civil, foi visto que a maioria é solteira. Mediante a estatística apresenta- 
da de acordo com o estado civil das adolescentes grávidas, percebe-se que os padróes segundo os quais a mulher só deveria ter filhos se existisse vida estável e se estivesse casada estão ultrapassados, pois a maioria das adolescentes, $31(60,7 \%)$ delas estão solteiras. E, muitas vezes, ao final da gravidez já não estão mais com o mesmo parceiro. Os dados encontrados coincidem com os dados de outros artigos sobre gravidez na adolescência. $O$ trabalho de Arcanjo et al., (2007) mostra que das 40 adolescentes investigadas, $55 \%$ das adolescentes vivem em união consensual; $20 \%$ são casadas e $25 \%$ são solteiras. $\mathrm{O}$ autor cita em seu trabalho a pesquisa de Gadelha (2002) sobre a vivência sexual de grávidas adolescentes referindo que $20 \%$ delas são casadas e $80 \%$ delas são solteiras. Sendo que algumas das solteiras vivem em regime de concubinato.

$\mathrm{Na}$ quarta pergunta relacionada à moradia foi visto que $24(47 \%)$ delas residem com os pais; 5 (9,8\%) residem na casa dos pais com o parceiro; 19 (37\%) residem com o parceiro e 2 (4\%) residem com outros familiares. Ao analisar estes dados verifica-se que a maioria delas continua a morar com a família, com ou sem o pai do bebê. Estes dados são corroborados por outras pesquisas e mostram que as grávidas não têm renda própria e sobrevivem com a ajuda dos pais, companheiros e/ou familiares. O que também está correlacionado com dependência financeira (GADELHA, 2002; ARCANJO et al., 2007).

Ao perguntar o tempo de duraçáo do relacionamento com o pai do bebê foi visto que $49 \%$ delas (25), tinha um relacionamento de 1 a 3 anos com o parceiro e outras $39 \%$ (20) tinham um relacionamento de 6 meses a 1 ano. Portanto, pode-se verificar que a maioria delas tinha um relacionamento com duração mais longa, entre 1 e 3 anos. Entretanto, ao analisar os dados percebe-se que em uma grande parte dos casos (39\%) o relacionamento foi de curto prazo. Nos casos onde foram verificados pequenos períodos entre o início da atividade sexual e a ocorrência da gravidez, esta pode ser decorrente da falta de experiência em relação à vivência da sexualidade. Seja mediante a ausência de informaçôes, expressa no desconhecimento sobre as alterações do próprio corpo, ou decorrente da despreocupação com a anticoncepção na iniciação sexual e no transcorrer do relacionamento. Quando a gravidez resulta de um namoro recente, ela assume o sentido de inesperada e não desejada. É um momento de difícil superação e constrangimento para essas adolescentes, em razão da gravidez decorrer de um namoro de pouca duração, em que não existia entre elas e os namorados nenhuma articulaçáo de projeto em comum, seja de união ou, muito menos, da vinda de filhos (Almeida, 2002).

A Figura 2 mostra a idade dos parceiros das adolescentes grávidas, e evidencia que a maioria dos parceiros
$(54,9 \%)$ possui idade superior a 20 anos, ou seja, não são adolescentes. Outro dado que a literatura aponta como fator associado à gravidez na adolescência é a idade do parceiro, geralmente maior. O mesmo foi verificado por Abeche et $a l$, (2007), que realizou um estudo com 309 gestantes adolescentes e evidenciou que a idade média dos parceiros foi 20 anos, sendo 4 anos a diferença de idade entre a paciente e seu companheiro. Somente metade dos parceiros era adolescente. Outros autores apontam o mesmo em suas pesquisas (PERSONA et al., 2004; PFITZNER et al., 2001; ABDALLAH et al., 1998).

Quando foi indagado quanto à escolaridade de cada uma (Figura 3), 53\% delas afirmaram ter abandonado a escola, sendo que $35 \%$ abandonaram no ensino fundamental e $17,6 \%$ abandonaram no ensino médio. As outras $47 \%$ continuam estudando, sendo que $21 \%$ cursam o ensino fundamental (do quinto ao nono ano) e $25 \%$ cursam o ensino médio. Quanto ao grande número de abandono escolar, resultante da gravidez entre as adolescentes, o mesmo dado foi constatado em vários estudos relacionados ao tema (PERSONA et al., 2004; PFITZNER et al., 2001; ARCANJO et al., 2007).

A Figura 4 retrata outra pergunta feita às adolescentes com relação à renda familiar; sendo visto que a maioria apresenta renda de 1 a 3 salários mínimos. Portanto, de acordo estes com estes dados, observa-se que quanto menor a renda familiar maior o número de gravidez na adolescência. Estudos anteriores encontraram valores de renda familiar inferiores a 5 salários-mínimos, similares a esta pesquisa. Entretanto, as adolescentes não contribuem com essa renda, sendo dependentes da família ou do parceiro (ABDALLAH et al., 1998; PERSONA et al., 2004; SPINDOLA \& SILVA, 2009).

Outra pergunta do questionário às gestantes adolescentes foi com relação aos assuntos discutidos no ambiente escolar e na Figura 5 estáo relacionadas as respostas, sendo que as adolescentes poderiam citar mais de um assunto: 32 $(62,7 \%)$ delas discutem mais sobre namoro; $17(33,3 \%)$ falam mais sobre sexualidade; $17(33,3 \%)$ sobre gravidez; 13 (25\%) sobre lazer; 11 (21\%) sobre moda; 11 (21\%) sobre alimentação; 7 (13,7\%) sobre anticoncepcionais e 14 $(27,4 \%)$ sobre outros assuntos. Através destas respostas observa-se que as adolescentes conversam na maioria das vezes sobre o namoro, porém poucas vezes conversam sobre a anticoncepção. $\mathrm{O}$ que pode resultar no aumento de gestações nesta fase da vida. Sendo verificado neste trabalho que elas não valorizam a discussão sobre anticoncepção no ambiente escolar.

Na Figura 6 foram relacionados os métodos contraceptivos que as adolescentes conhecem. No questionário, poderiam marcar mais de uma opção: 41 (80\%) delas relatam que 
conhecem a camisinha; $33(64,7 \%)$ delas conhecem a pílula anticoncepcional; 10 (19,6\%) conhecem o DIU; 4 (7,8\%) conhecem o diafragma; 4 (7,8\%) conhecem a tabelinha e 6 $(11,7 \%)$ não conhecem nenhum método contraceptivo. Portanto, observa-se neste estudo, que a maioria das adolescentes grávidas conhece ou já ouviu falar de métodos contraceptivos, sendo a pílula anticoncepcional e a camisinha os mais conhecidos. Estes dados também foram relatados por outros autores na literatura (DIAS \& TEIXEIRA, 2010; SPINDOLA \& SILVA, 2009; KRAFT, 1993).

Outra pergunta estava relacionada ao método anticoncepcional que utilizam ou utilizavam antes de engravidar. Elas podiam marcar mais de uma opção. Grande parte das adolescentes grávidas (41\%) respondeu que não utilizavam nenhum método contraceptivo; 17 (33,3\%) delas se referiam uso de camisinha; 15 (29,4\%) usavam pílula anticoncepcional; 2 (3,9\%) usavam a tabelinha; 1 (1,9\%) usava o DIU. Como se verifica, um número elevado de adolescentes, $41 \%$ delas, não utilizava nenhum método contraceptivo, apesar das distribuiçóes gratuitas em postos de saúde. $\mathrm{O}$ que pode gerar além da gravidez indesejada, o risco de adquirir doenças sexualmente transmissíveis (DSTs). De acordo com os dados, 32 (62,7\%) das adolescentes relataram ter utilizado algum método, como camisinha e pílula, em algumas de suas relaçôes sexuais. Estes dados estão de acordo com os dados da literatura vista nesta pesquisa (DIAS \& TEIXEIRA, 2010; SPINDOLA \& SILVA, 2009; ARCANJO et al., 2007; PERSONA et al., 2004).

O trabalho de Persona et al. (2004) revelou, em conformidade com a literatura, que a pílula foi o contraceptivo mais utilizado entre as adolescentes. Seguido pelo hormônio injetável em segundo lugar. Já o uso do preservativo masculino ficou em terceiro lugar e deixou a desejar, visto ser a única maneira de prevenir as doenças sexualmente transmissíveis.

O trabalho de Arcanjo et al., (2007) relata que mesmo tendo acesso aos anticoncepcionais, as adolescentes não usam adequadamente, porque não acreditam na possibilidade de engravidar. Em razão da pouca freqüência dos relacionamentos sexuais, consideram-se constantemente em um período seguro, acham os contraceptivos difíceis de serem obtidos e incômodos, e partem da premissa de que isso "não vai acontecer comigo". Além disso, acham os contraceptivos antinaturais, perigosos, principalmente a pílula "que vai engordar". Baseados em informaçôes genéricas, os rapazes pensam que a camisinha diminui o prazer sexual; a não-utilização dos métodos pode acontecer pelo desejo inconsciente de engravidar ou de engravidar alguém para verificar sua capacidade reprodutiva; medo dos pais descobrirem o anticoncepcional e das represálias.

A última pergunta do questionário foi com relação ao planejamento da gravidez. A figura 7 mostra os dados das respostas, onde se verifica que $34(66,6 \%)$ das adolescentes relatam terem engravidado ao acaso; $14(27,4 \%)$ planejaram a gravidez e $3(5,8 \%)$ afirmaram que a gravidez foi indesejada. Portanto, pode-se sugerir, de acordo com os dados obtidos neste estudo que a maioria das adolescentes grávidas não tinha a intenção de engravidar, ou seja, das 51 gestantes, 37 $(72,5 \%)$ não desejavam engravidar. Estes dados são concordantes aos resultados da literatura (SPINDOLA \& SILVA, 2009; ARCANJO et al., 2007; SABROZA et al., 2004)

Sabroza et al., (2004) realizaram uma pesquisa no município do Rio de Janeiro, onde se constatou que 69,1\% das puérperas com idade de $12-16$ anos e $61,4 \%$ com idade de 17-19 anos não desejaram a gravidez. Assim, pode-se observar que a gestação na adolescência pode estar relacionada com o início precoce da atividade sexual desprotegida.

Desta forma, os programas para adolescentes que tratam de temas como sexualidade, gravidez, prevençáo de doenças sexualmente transmissíveis e AIDS devem, sobretudo, considerar os aspectos sociais, culturais e econômicos da comunidade em que são desenvolvidos, para que possa atuar com êxito nesta situação.

De acordo com Spindola \& Silva (2009), em muitas situaçóes, as jovens desconhecem a dinâmica do seu corpo, seus hormônios e os perigos de uma gestação não planejada. $\mathrm{O}$ não-planejamento deve-se, portanto, à falta de orientação ou de oportunidade de acesso aos métodos contraceptivos, o que ocorre comumente com as adolescentes. Por esse motivo, é de extrema importância a implementação da realização do planejamento familiar com incentivo à proteção para prevenção da gravidez não desejada.

Portanto, a introdução do vídeo com orientaçôes para prevenção da gestaçáo não desejada na adolescência pode esclarecer sobre o uso dos contraceptivos. Como no trabalho de Antunes et al. (2011), que após a exposição do vídeo "Drogas: um caminho para o fim" notou-se que esta tecnologia educacional foi eficaz em sala de aula uma vez que proporcionou grandes benefícios na prática pedagógica como um recurso de maior atração e motivação para o processo educativo. Foi possível perceber durante toda a metodologia desenvolvida que os educandos tiveram momentos reflexivos acerca do assunto abordado. Identificou-se por meio dos registros e falas dos estudantes um maior compromisso e clareza das informaçóes no combate às drogas. Os estudantes ao participarem das discussóes mostraram-se ativos em seu desenvolvimento cognitivo e no processo de ensino-aprendizagem e foram sensibilizados quanto aos perigos que é o uso de drogas psicotrópicas.

No estudo de Peluso et al. (2010), de acordo com relatos dos alunos, também percebeu-se como boa a iniciativa de usar recursos informatizados, pois os mesmos relataram 
que através dos vídeos eles realmente conseguiram entender a maneira correta de realizar a prática e o estudo, sugerindo que com a utilização da tecnologia é possível ao discente potencializar sua aprendizagem dos assuntos abordados na aula teórica e facilitar os aprendizados das aulas práticas.

Desta forma, o vídeo poderá ser uma ferramenta a mais a ser utilizada na orientação do uso correto dos métodos contraceptivos aos adolescentes. O que é corroborado por Struchiner (2011), quando afirma que inovar com o uso de Tecnologias de Informação e Comunicação na educação não significa a simples introdução destas ferramentas, mas a reflexáo sobre como estas podem ser construídas e implementadas de maneira a trazer qualidade para o cenário educacional, isto é, a sua capacidade de melhorar a prática corrente (CARDOSO, 2002).

\section{CONSIDERAÇÓES FINAIS:}

Á partir dos dados coletados nesta pesquisa sugere-se que existe uma associação entre desinformação, baixa escolaridade, situação de pobreza e gravidez em idade precoce.

A autora percebeu que as informaçóes sobre anticoncepção existem, porém as adolescentes não absorvem as informaçôes como deveriam, sendo, portanto, necessário que a atenção à sexualidade e à saúde reprodutiva apresente um papel de maior importância na educação das meninas, para que elas tenham o livre arbítrio de escolher o momento certo de engravidar.

E os meninos também ocupam um lugar nessa história, aprendendo a prevenir a gravidez e as DST com o estímulo ao uso da camisinha. Pois, as possibilidades que os adolescentes têm de disporem de métodos contraceptivos de baixo custo ou até gratuitos são reais, já que há a distribuição gratuita de anticoncepcionais hormonais e camisinha nos postos de saúde.

O que a autora desejava descobrir após esta pesquisa é se a gravidez é uma experiência esperada ou indesejada na adolescência. E foi percebido com os dados da pesquisa que a maioria das adolescentes teve uma gestação não planejada, revelando que há a necessidade de se incrementar o ensino sobre orientação sexual e anticoncepção.

Então, durante o estudo percebeu-se que as consequências do uso incorreto dos contraceptivos ou simplesmente fato de não usá-los, gera um grande número de gestaçóes não planejadas na adolescência. E para auxiliar na sua prevenção será necessário que profissionais de saúde estabeleçam um relacionamento de confiança com essas adolescentes. A adolescente deve receber apoio psicológico nesse momento, além de orientaçóes sobre métodos contracepti- vos, pré-natal e apoio da família, companheiro e sociedade. Além disso, é preciso ouvir e valorizar os sentimentos e preocupaçóes dos jovens para conhecer o mundo adolescente: as pressóes e os constrangimentos podem dar pistas das dificuldades que enfrentam na hora de optar e usar um método anticoncepcional, e dos entraves para a negociação dos métodos entre parceiros.

A partir do descrito, sugere-se à equipe de saúde realizar palestras dirigidas aos adolescentes, utilizando recursos didáticos que os sensibilizem para o uso de métodos contraceptivos; sensibilizar a equipe multiprofissional para o trabalho com adolescentes, incentivando seu maior empenho nos programas de assistência a esse grupo; e, desenvolver o trabalho com grupos de adolescentes a partir das necessidades apontadas por eles para que sejam atores ativos nesse processo, o que contribuirá na sua formação para a vida e o mundo. Para tanto, a equipe de saúde da família necessita estar capacitada e desenvolver continuamente açóes de promoção da saúde junto a esta população.

Assim, a prática da medicina em postos de saúde, os resultados desta pesquisa e a atualidade fizeram com que produzisse um vídeo que se espera ser divulgado em espaços formais e não formais. Pois, desta forma, as intervençóes educativas realizadas e as novas tecnologias, neste caso, o vídeo, podem auxiliar no ensino e chamar mais a atençáo das adolescentes. $\mathrm{O}$ vídeo por ter uma linguagem mais parecida com a delas pode ser um instrumento para ajudar na diminuição dos índices de gestação não planejada na adolescência.

\section{REFERÊNCIAS BIBLIOGRÁFICAS:}

1. ABDALLAH, Vânia Olivetti Steffen et al. Gravidez na adolescência: experiência em um hospital universitário. Pediatria Moderna; v. 34, n.9, p. 561-70. 1998.

2. ABECHE, Alberto Mantovani et al. Aspectos sócio-econômicos do parceiro da gestante adolescente. Rev. HCPA, Porto Alegre, v. 27, n.1, p. 5-9. 2007.

3. ALTMANN, Helena. Orientação sexual nos parâmetros curriculares nacionais. Rev. Estud. Fem., v. 9, n.2, p. 575-585. 2001. ISSN 0104-026X.

4. ALVARENGA, Jenner Procópio et al. Livro de ciências integradas do $8^{\circ}$ ano. $1^{\text {a }}$ edição. Curitiba: Editora positivo. 2008.

5. ANTUNES, Adriana Maria; CRUZ,Vanessa Rafaela Milhomem; MENEZES, Joana Cristina Neves. Uso 
de recursos áudio-visuais em sala de aula para sensibilização da comunidade escolar contra as drogas psicotrópicas. - Goiás-- Ensino, Saúde e Ambiente .V4 (3), pp. 93-105, dez. 2011. ISSN 1983-7011

6. ARCANJO Conceição Maria; OLIVEIRA, Maria Ivoneide Veríssimo; BEZERRA, Maria Gorete Andrade. Gravidez em adolescentes: unidade municipal, Fortaleza - CE. Esc Anna Nery R Enferm. set; 11 (3): 445 $-51.2007$.

7. CARDOSO, Ana Paula. A Receptividade à Mudança e à Inovaçáo o Professor e o Contexto Escolar. Porto: Asa Editores, 2002. 128p.

8. CERQUEIRA-SANTOS et al. Gravidez na adolescência: análise contextual de risco e proteção. Psicologia em Estudo, Maringá, v. 15, n. 1, p. 73-85, jan/mar. 2010

9. DIAS, Ana Cristina Garcia; TEIXEIRA, Marco Antônio Pereira. Gravidez na adolescência: um olhar sobre um fenômeno complexo. Paidéia, Ribeirão Preto, v. 20, n. 45, p. 123-131. jan/Abr. 2010. ISSN 0103$863 \mathrm{X}$

10. FAVALI, Leonel Delvai; PESSÔA, Karina Alessandra; ANGELO Elisangela, Andrade. Livro de ciências do $8^{\circ}$ ano projeto radix: raiz do conhecimento, Londrina: Editora Scipione, 2009.

11. FIGUEIREDO, Bárbara. Maternidade na adolescência: do risco à prevenção. Revista Portuguesa de Psicossomática, Porto, v. 3, n. 2, p. 221-237. jul/dez. 2001.

12. GADELHA, EGC. Adolescente grávida: abordagem sobre sua vivência sexual [monografia de especialização]. Sobral (CE): Universidade Estadual Vale do Acaraú / UVA; 2002

13. KRAFT, Pal. Sexual Knowledge among Norwegian adolescents. Journal of Adolescence, Norway, v.16, n.1, p.3-21, mar. 1993

14. MOREIRA, Thereza Maria Magalhães et al. Conflitos vivenciados pelas adolescentes com a descoberta da gravidez. Rev. esc. enferm. USP [online]. vol.42, n.2, p. 312-320. ISSN 0080-6234. 2008.
15. MINISTÉRIO DA SAÚDE. Saúde sexual e saúde reprodutiva de adolescentes e jovens. Brasília- Brasil: Marco teórico e referencial. 2006. Disponível em: <http://www.saude.gov.br/ >. Acesso em 15 out. 2010

16. PELUSO, Emília Miranda et al . X JORNADA DE ENSINO, PESQUISA E EXTENSÃO. 18 a 22 de outubro, 2010. Recife- uso de recursos didáticos informatizados no ensino da disciplina técnica cirúrgica veterinária- JEPEX - UFRPE.

17. PERSONA, Lia; SHIMO, Antonieta Keiko Kakuda; TARALLO, Maria Celina. Perfil de adolescentes com repetição da gravidez atendidas num ambulatório de pré-natal. Rev. Latino-Am. Enfermagem. v.12, n.5, pp. 745-750. 2004.ISSN 0104-1169.

18. PFITZNER, Mark; HOFF, Charles; MCELLIGOTT, Kathleen. Repeat pregnancy in program for pregnant and parenting teens: 15 years of experience. J Adolesc Health,v. 28, n.2, p.129, february . 2001.

19. SABROZA, Adriane Reis et al. Perfil sócio-demográfico e psicossocial de puérperas adolescentes do Município do Rio de Janeiro, Brasil - 1999-2001. Cad. Saúde Pública, Rio de Janeiro, v.20 n. 1, p.112-120, 2004.

20. SANTANA, Olga e FONSECA, Aníbal. Livro de Ciências Naturais do $7^{\circ}$ ano, São Paulo: Editora saraiva. 2009.

21. SPINDOLA, Thelma; SILVA, Larissa Freire Furtado da. Perfil epidemiológico de adolescentes atendidas no pré-natal de um hospital universitário. Esc Anna Nery Rev Enferm. v.13, n.1, p. 99-107, jan/mar. 2009.

22. STRUCHINER, Mirian. Análise do Processo de Integração de Tecnologias de Informação e Comunicação em Atividades Educativas no Ensino Fundamental no Contexto do "Programa Um Computador por Aluno” (PROUCA). UFRJ. Núcleo de Tecnologia Educacional para a Saúde Laboratório de Tecnologias Cognitivas Edital CNPq/CAPES/SEED-MEC no 76/2010 Fevereiro - 2011 - ltc-ead.nutes.ufrj.br

23. VIEIRA, Leila Maria et al. Reflexôes sobre a anticoncepção na adolescência no Brasil. Rev. Bras. Saude Mater. Infant. [online]. v.6, n.1, p. 135-140. 2006. ISSN15193829 


\section{FIGURAS:}

\section{Adolescentes grávidas}

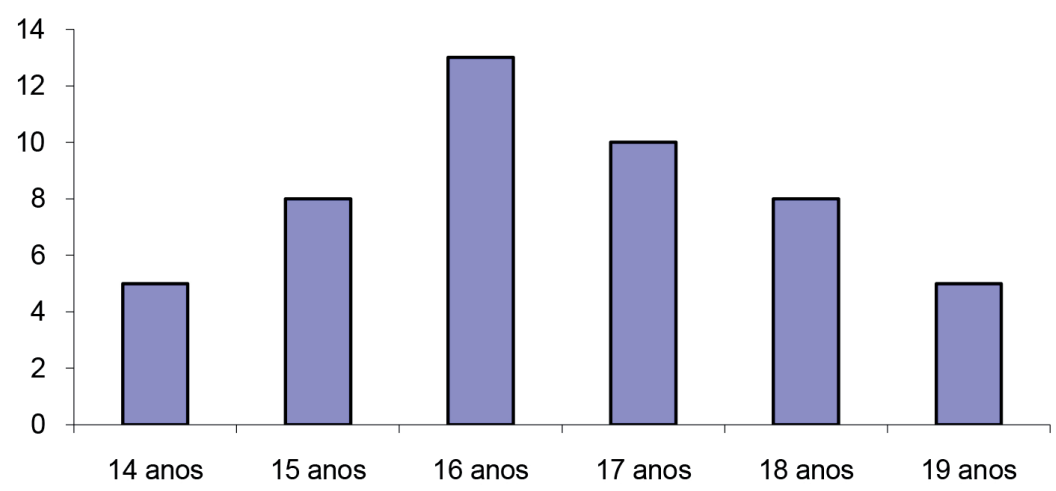

Figura 1: Distribuição da amostra segundo a faixa etára.

\section{Idade do parceiro}

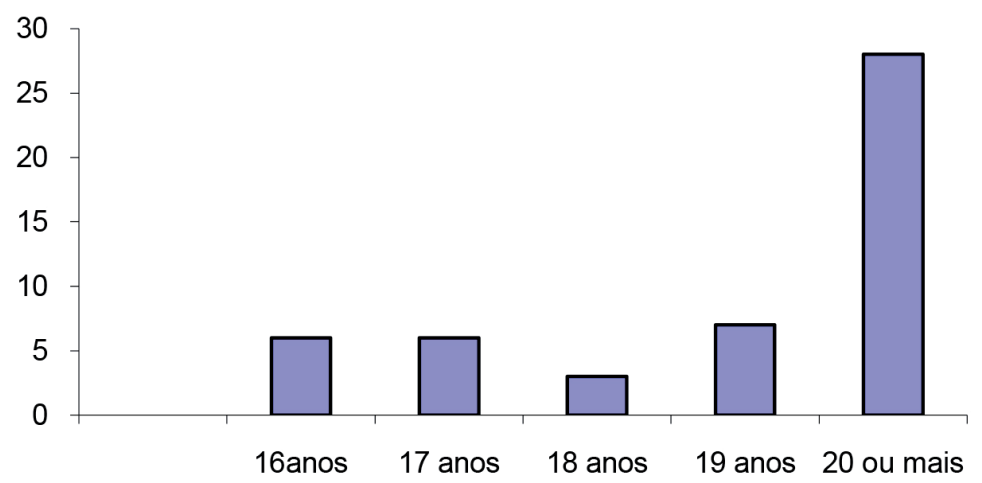

Figura 2: Distribuição da amostra segundo a idade do parceiro

Esculal Iuaue ua auviescellte ylaviua

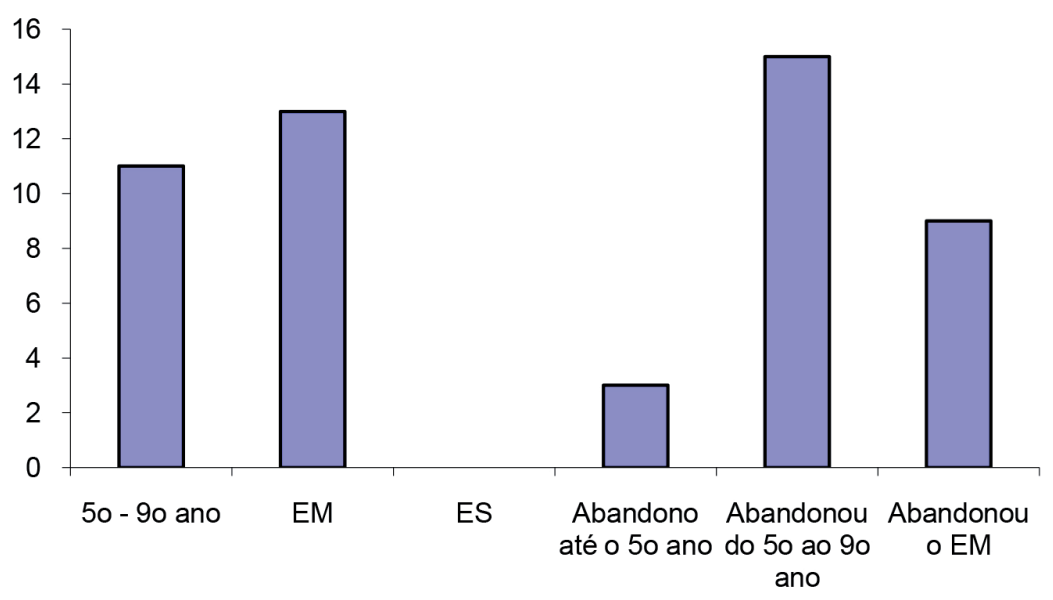

Figura 3: Distribuiçáo da amostra segundo a escolaridade 


\section{Renda Familiar das Adolescentes}

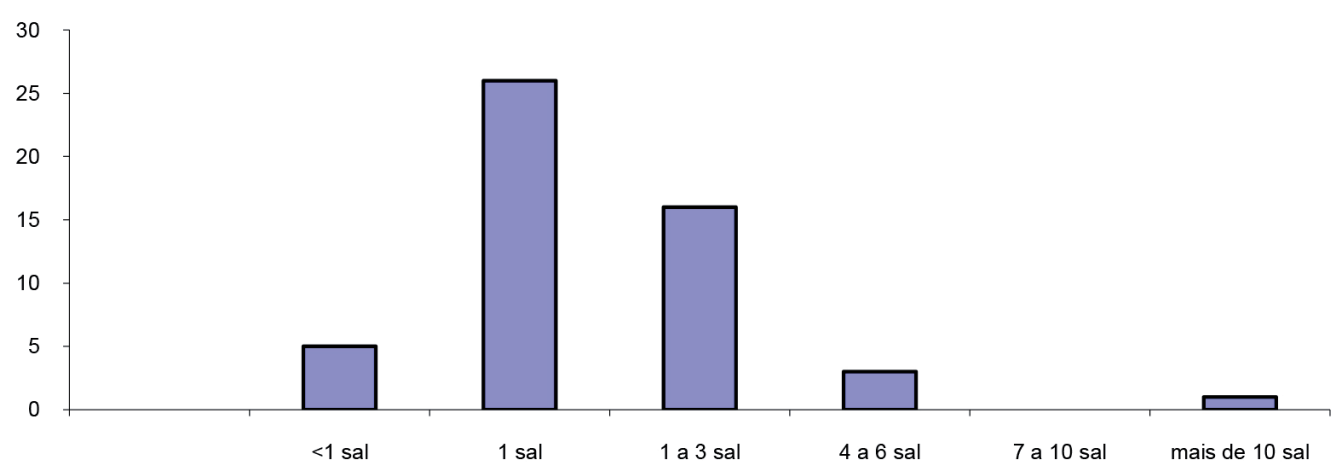

Figura 4: Distribuição da amostra segundo a renda familiar das adolescentes

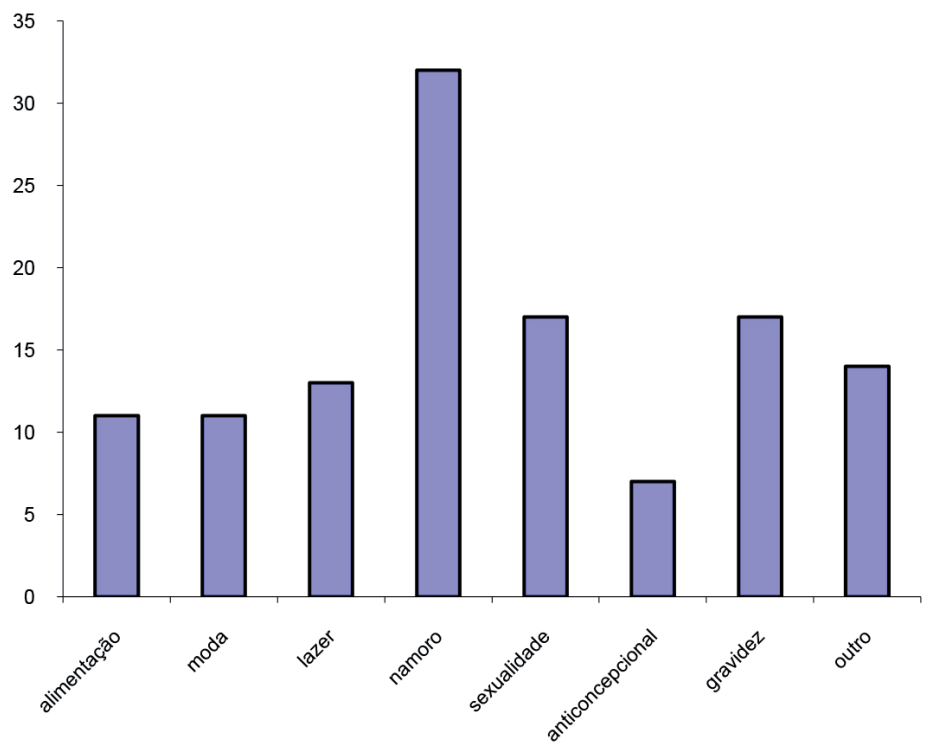

Figura 5: Distribuição da amostra segundo assuntos discutidos na escola

Quais métodos contraceptivos você conhece?

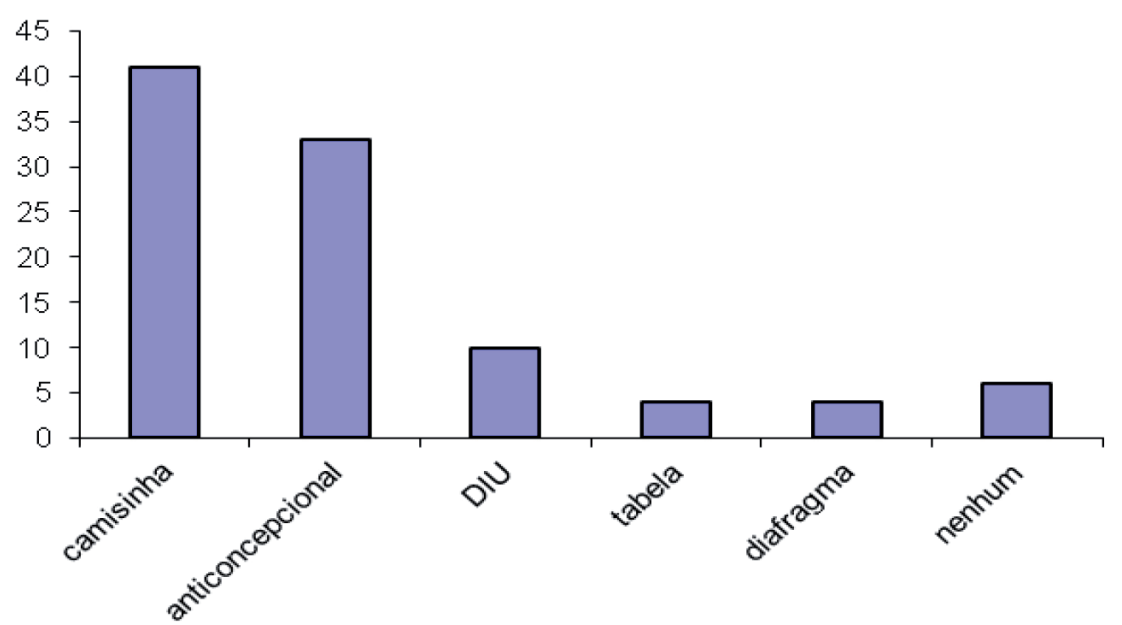

Figura 6: Distribuição da amostra segundo métodos contraceptivos que conhecem 


\section{A sua gravidez foi?}

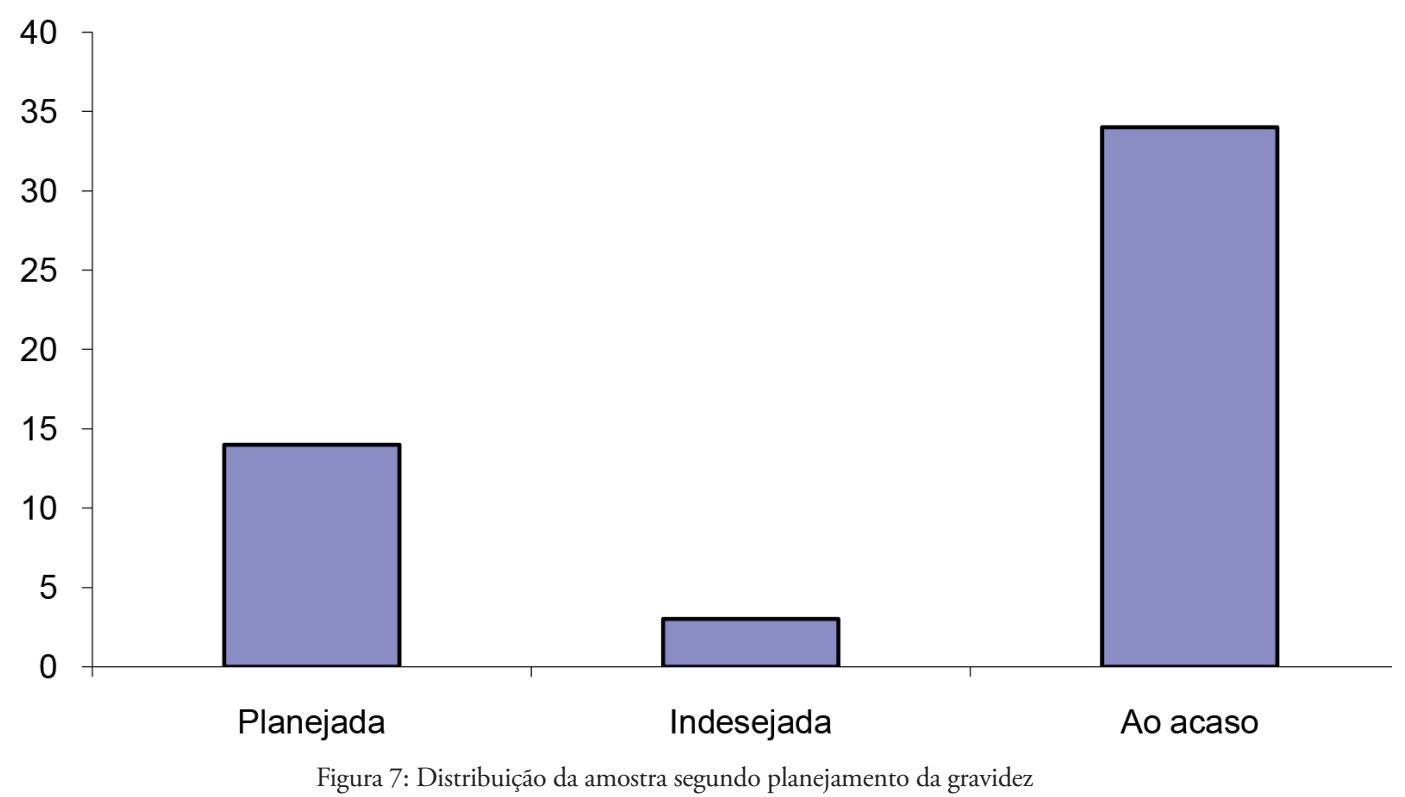

